\title{
Medico-legal methods to confirm the male sexual dysfunction in front of the Libyan courts
}

\begin{abstract}
Erectile Dysfunction (ED) is a social problem which causes trouble to the couple. The woman litigates a lawsuit in front of the courts to be divorced from her husband. This work was done to design an accurate simple and applicable scheme for conclusive diagnosis of male erectile dysfunction.One hundred patients with ED collected from the Medico-legal center of Tripoli, Zawia and Sabratha. In cooperation with Urology center clinic as outpatient. Andrology Dept. outpatients' clinics of Tripoli hospitals their ages ranged from 2260 years. These patients were evaluated by history, clinical examination and investigation (Intracavesnosal injection (ICI), Doppler for penile vasculature and Rigdiscan. The results revealed that from history 42 patients were suspected to have psychogenic ED, 38 patients had organic causes of ED and 20 patients of them the cause of ED was unknown. By ICI, 48 gave normal response (means psychogenic ED) and 52 of them gave subnormal response.

By Doppler for 52 cases 46 cases had organic and vascular causes of ED while, 6 cases still unknown. By Rigiscan for the 6 cases 3 of them were psychogenic, and the remaining 3 had organic causes of ED. The end results were 51 patients had psychogenic factor related to ED and 49 patients had organic factor relegated to ED. There was a significant relation between age and type of ED \& a significant relation between special habit and organic ED. The psychegenic ED had a significant time course in relation to the organic ED as it had a sudden and acute onset as regard for its occurrence. So this study recommended that for conclusive diagnosis for the cases of ED, the present sheet should be applied. Also ICI and Doppler as methods for diagnosis of ED are still having important role in this aspect. The using of rigiscan is the best available and objective test.
\end{abstract}

Keywords: Erectile dysfunction, psychogenic causes, organic causes, rigiscan, doppler, Intra corporal injection.
Volume 7 Issue 5 - 2019

\author{
Fathi Mohamed Alatrash,' Muftah Elgarba ${ }^{2}$ \\ 'Forensic Medicine and Toxicology, Faculty of Medicine-Zawia \\ University, Libya \\ ${ }^{2}$ Associated Prof. of Urology, Faculty of Medicine-Omer \\ Elmokhtar University, Libya
}

Correspondence: Fathi Mohamed Alatrash, Forensic Medicine and Toxicology, Faculty of Medicine-Zawia University, Libya, Emaildrfathiat@yahoo.com

Received: March 18, 2019| Published: October 02, 2019
Abbreviations: ED, erectile dysfunction; ICI, intra cavernosal injection; NPT, nocturnal penile tumescent; $\mathrm{BPH}$, benign prostatic hyperplasia; ACE, angiotensin converting enzyme inhibitors; VCD, vacuum constriction device

\section{Introduction}

Erectile dysfunction, or ED, is the most common sex problem men report to their doctor ED is defined as trouble getting or keeping an erection that's firm enough for sex. Though it's not rare for a man to have problems with erections from time to time, ED that comes on slowly over time or regularly with sex is not normal. ${ }^{1}$ The sexual function and the sexual dysfunction have only recently been discussed openly in most societies and cultures. The sexual penile erection includes: the psychogenic erection that occurs as a result of psychogenic stimulation as during imagination, sexual thoughts and visual or auditory stimulation. The reflexogenic erection occurs as a result of reflex direct stimulation of the penis for example, tactile stimulation of the penis. ${ }^{2}$ The penile erection is formed of two stages; the tumescence which is derived from the Latin word that means swelling. The second stage is the rigidity of the corpora cavernosa due to the increased blood pressure of the cavernous spaces. ${ }^{3}$ There are four crucial physiological requirements for penile rigidity; intact neuronal innervations, intact arterial supply, appropriately responsive corporal smooth muscles and intact venous mechanisms. ${ }^{4}$ Erectile dysfunction (E.D.) is defined as the persistent inability to obtain or to maintain penile erection sufficient for satisfactory sexual intercourse and this term has replaced the obsolete term impotence. ${ }^{5}$

Erectile dysfunction affects and 152 million men worldwide, it is projected to affect 322 million men worldwide by 2025. I affect 30 million men in the USA alone. ${ }^{6}$ It may lead to a social problem which cause troubles to the couple by making them unsatisfied of their sexual life and also cause some degree of personal distress. ${ }^{7}$ The unsatisfied or repeated failure in the sexual intercourse for the couple due to the male sexual dysfunction may lead to the divorce or the woman litigating a lawsuit in front of the courts to be divorced from her husband due to his ED. However, it is difficult to reach a final diagnosis in some cases of male sexual dysfunction and whether the cause of this dysfunction is curable or not which may affect negatively the decision taken by the judge in the divorcement cases. So the aim of this work is to design an accurate, simple and applicable scheme for conclusive diagnosis of male sexual dysfunction. Also to differentiate between the treatable and the untreatable cases of male sexual dysfunction to make a conclusive diagnosis in cases of illegitimate divorce to take a decision in the divorcement cases to the Libyan courts based on accurate, scientific and medico legal basis.

\section{Subjects and methods}

\section{Subjects}

One hundred patients complaining of erectile dysfunction were 
selected to be included in this study (after taking oral consent). Those patients were collected from the Medico-legal center of Tripoli, Zawia and Sabratha. In cooperation with Urology center clinic as out-patient in the period from April 2014 to October 2017. The age of the patients ranged from 22-60 years (Mean 40.5 \pm 8.5 ).

\section{Methods}

The patients were subjected to:

Full medical history, Careful clinical examination, Investigation; such as:

Laboratory investigations: Urine analysis, complete blood count, Blood glucose levels, fasting and 2 hours post prandial, Liver and kidney functions tests.

Hormonal assay as: Serum level of testosterone, serum level of prolactin, serum level of F.S.H, serum level of L.H

\section{Specific investigations}

Intra cavernosal pharmaco test (I.C.I):

This test was done according to Viraj ${ }^{8}$ detect degrees of erection.

$\mathrm{E} 0=$ No erection at all.

$\mathrm{E} 1=$ Partial erection is not capable of penetration even with manual assistance.

$\mathrm{E} 2=$ Partial erection capable of penetration with manual assistance.

E3 =Early full erection sufficient for spontaneous penetration.

E4 $=$ Full erection with partial penetration.

E5 $=$ Full erection with full rigidity.

E6 $=$ Priapism.

The possibilities of the resopnse: ${ }^{9}$

i. If the patient has full rigid erection (E5) that starts within 10 minutes and lasts for at least 40 minutes, denoted positive erectile response or means that the patient has a psychogenic cause of erectile dysfunction.

ii. If the patient has full rigid erection (E5) that starts within 10 minutes and lasts for more than 2 hours, he may have neurogenic E D as brain lesions, spinal cord, or peripheral nerve lesion for further evaluation.

iii. If Full erection presists for 4 hours, this is considered as priapism (Androgenic emergency) and dealt with by injecting diluted ephidren $(1 \mathrm{ml}$ ephidren + saline $10 \mathrm{ml})$ slowly in the corpora cavernosa and it can be prevented by giving the patient oral terbutatine tablets in a dose of $(5-10 \mathrm{mg})$ just before the test as it is sympathomimetic drug that act within 30-120 minutes.

iv. A slow or weak erectile response (E0-E4) taking 30 minutes or more, suggests arteriogenic ED for further evaluation.

v. If the patient has initial good erectile response (E5) that is not maintained for more than 15 minutes, he may have corporavenogenic ED for further evaluation.

vi. If the patient has both delayed or weak erectile response (E0E4). As well as early loss of this response, he may have both arteriogenic and corporo-venogenic ED for further evaluation.

\section{Pharmaco-duplex doppler ultrasonographic examination of the cavernosal blood vessels}

This test was done according to ${ }^{10}$ the possibilities of Duplex doppler ultrasonography: to detect the following either:

a. Normal penile vasculature,

b. Arteriogenic cause of E D,

c. Venogenic cause of E D,

d. Mixed arteriogenic and venogenic causes of ED

\section{Nocturnal penile tumescence (NPT) monitoring by Rigiscan}

This test aims to differentiate between psychogenic and organic ED through graphic record. ${ }^{11}$ The patients classified into two main groups according to the cause of ED, psychogenic and organic groups of erectile dysfunction.

\section{Results}

The ages and frequencies of the special habits of the 100 studied patients are shown in Table 1. The onset of occurrence of $\mathrm{ED}$, the frequency of morning erection among the patients, and the cooperation of the wives are shown in Table 2. From the detailed history, psychometric description of psychiatric disorders and physical examination, 42 patients ( $42 \%$ ) suspected to have psychogenic causes of ED while 38 patients ( $38 \%$ ) suspected to have organic causes of ED but 20 patients $(20 \%)$ were unknown. As shown in Table 3 as regard the results of the intracavernosal injection test (I.C.I) that done to the 100 cases, 52 cases showed subnormal response to the upgrading dosage of (I.C.I) testing as shown in Table 4, they were candidated for pharmaco-duplex Doppler, the results revealed that 22 cases show normal penile vasculature with history of medical causes of ED, while 6 cases show normal penile vasculature with unknown causes and 24 cases were of abnormal vasculature whom considered having organic $\mathrm{ED}$, of them 16 cases had mixed vasculogenic and medical causes of ED such as (vasculogenic ED + hypertension, D.M., coronary insufficiency or C.O.P.D.) while the other 8 cases had pure vascular causes of ED shown in Tables 5 \& 6 .

Table I Showing age and special habits of the studied patients

\begin{tabular}{|c|c|c|c|}
\hline Item & Demographic data & $\begin{array}{l}\text { No. of } \\
\text { Patients }\end{array}$ & Percentage \\
\hline \multirow[t]{4}{*}{ Age } & $20-30$ & 17 & $17 \%$ \\
\hline & $31-40$ & 16 & $16 \%$ \\
\hline & $4 \mid-50$ & 35 & $35 \%$ \\
\hline & above 50 & 32 & $32 \%$ \\
\hline \multirow[t]{5}{*}{ Special Habits } & Tobacco smoking & 52 & $52 \%$ \\
\hline & Alcoholism & 5 & $5 \%$ \\
\hline & Hashish -Bango & 7 & $7 \%$ \\
\hline & $\begin{array}{l}\text { Mixed } 2 \text { or more of the } \\
\text { above }\end{array}$ & 6 & $6 \%$ \\
\hline & No special habits & 30 & $30 \%$ \\
\hline
\end{tabular}


Table 2 Showing History \& Complaints of the Studied Patients

\begin{tabular}{llll}
\hline Item & $\begin{array}{l}\text { Criteria of } \\
\text { classification }\end{array}$ & $\begin{array}{l}\text { No. of } \\
\text { Patients }\end{array}$ & Percentage \\
\hline The onset of ED & $\begin{array}{l}\text { Since marriage } \\
\text { Acutely (within days } \\
\text { to weeks) } \\
\text { Gradually within } \\
\text { months }\end{array}$ & 33 & $17 \%$ \\
Morning Erection & $\begin{array}{l}\text { Present } \\
\text { Not present }\end{array}$ & 29 & $33 \%$ \\
& Not sure & 32 & $50 \%$ \\
Wives & Cooperative & 39 & $32 \%$ \\
Cooperation & Non-cooperative & 39 & $39 \%$ \\
\hline
\end{tabular}

Table 3 Showing suspected causes of ED

\begin{tabular}{|c|c|c|c|}
\hline Suspected cause & $\begin{array}{l}\text { Manifestation \& } \\
\text { disease }\end{array}$ & $\begin{array}{l}\text { No. of } \\
\text { patient }\end{array}$ & Percentage \\
\hline $\begin{array}{l}\text { Psychiatric } \\
\text { manifestations }\end{array}$ & $\begin{array}{l}\text { Disturbed general } \\
\text { appearance }\end{array}$ & 5 & $5 \%$ \\
\hline \multirow[t]{7}{*}{ No. $=42$} & Disturbed speech & 4 & $4 \%$ \\
\hline & Disturbed mood & 14 & $14 \%$ \\
\hline & $\begin{array}{l}\text { Disturbed } \\
\text { consciousness }\end{array}$ & 5 & $5 \%$ \\
\hline & Disturbed orientation & 4 & $4 \%$ \\
\hline & Hallucination & 3 & $3 \%$ \\
\hline & Disturbed memory & 4 & $4 \%$ \\
\hline & Disturbed judgement & 3 & $3 \%$ \\
\hline Organic Diseases & Hypertension & 13 & $13 \%$ \\
\hline \multirow[t]{5}{*}{ No. $=38$ cases } & Cardiac & 7 & $7 \%$ \\
\hline & C.O.P.D & 4 & $4 \%$ \\
\hline & D.M. & 12 & $12 \%$ \\
\hline & Chronic Hepatic & I & $1 \%$ \\
\hline & prostatic Hyperplasia & I & $1 \%$ \\
\hline \multicolumn{4}{|c|}{ Table 4 Showing Response of the studied patients on (I.C.I) testing } \\
\hline \multirow[t]{2}{*}{$\begin{array}{l}\text { Dosage of } \\
\text { administration }\end{array}$} & \multirow[t]{2}{*}{$\begin{array}{l}\text { Total no of } \\
\text { studied patient }\end{array}$} & \multicolumn{2}{|c|}{ No. of Patients } \\
\hline & & $\begin{array}{l}\text { Normal } \\
\text { response }\end{array}$ & $\begin{array}{l}\text { subnormal } \\
\text { response }\end{array}$ \\
\hline 15 mg (0.5 ml) & 100 & II & 89 \\
\hline $30 \mathrm{mg}(\mathrm{l} \mathrm{ml})$ & 89 & 27 & 62 \\
\hline 60 mg (2 ml) & 62 & 10 & 52 \\
\hline
\end{tabular}

Table 5 Showing results of pharmaco duplex-Doppler ultrasonography

\begin{tabular}{lll}
\hline Findings & $\begin{array}{l}\text { No. of } \\
\text { patients }\end{array}$ & Percentage \\
\hline Normal penile vasculature & 28 & $53.80 \%$ \\
Arteriogenic & 7 & $13.50 \%$ \\
corporo -venogenic & 9 & $17.30 \%$ \\
Mixed arteriogenic and corporovenogenic & 8 & $15.40 \%$ \\
Total no of studied patient & 52 & $100 \%$ \\
\hline
\end{tabular}

Table 6 Showing results obtained from the duplex Doppler \& history of medical diseases

\begin{tabular}{|c|c|c|c|c|}
\hline \multicolumn{2}{|c|}{ Criteria of classification } & $\begin{array}{l}\text { No. of } \\
\text { patients }\end{array}$ & $\%$ & $\begin{array}{l}\text { Total No. of } \\
\text { patients }\end{array}$ \\
\hline \multicolumn{2}{|c|}{ Pure medical causes of ED } & 22 & $42.30 \%$ & \multirow{4}{*}{$\begin{array}{l}\text { Normal penile } \\
\text { vasculature } \\
(28)\end{array}$} \\
\hline Unknown caus & & 6 & $11.50 \%$ & \\
\hline \multicolumn{2}{|c|}{ Pure vasculogenic causes } & 8 & $15.40 \%$ & \\
\hline Mixed & $\begin{array}{l}\text { Vascular + } \\
\text { hypertension. }\end{array}$ & 7 & $13.50 \%$ & \\
\hline \multirow{3}{*}{$\begin{array}{l}\text { Vasculogenic } \\
\text { and other } \\
\text { medical causes }\end{array}$} & $\begin{array}{l}\text { vascular + } \\
\text { D. M. }\end{array}$ & 5 & $9.60 \%$ & \multirow[t]{3}{*}{$\begin{array}{l}\text { vasculogenic } \\
\text { causes (24) }\end{array}$} \\
\hline & $\begin{array}{l}\text { vascular + } \\
\text { coronary }\end{array}$ & 3 & $5.80 \%$ & \\
\hline & $\begin{array}{l}\text { Vascular + } \\
\text { COPD }\end{array}$ & 1 & $1.90 \%$ & \\
\hline
\end{tabular}

As regard the above unknown 6 cases that complained of ED and did not respond to the (I.C.I) testing and by doing the pharmacoduplex doppler revealed that they are of normal penile vasculature so, they were candidate for nocturnal penile tumescent (NPT) monitoring by Rigiscan that revealed that 3 cases among them had psychoginc ED while the other 3 cases had organic causes of ED for further evaluation and investigations, the results of these investigations revealed that 1 patient of them had hypercholesterolemia and by doing stress ECG testing revealed that he have coronary insufficiency, while 1 patient had chronic hepatitis of alcoholic form due to excessive alcoholic intake (he hidded this special habit of alcoholic intake in the history), while the last patient have hyperthyroidism (thyrotoxicosis) detected laboratory. The I.C.I. give $94.1 \%$ sensitivity in diagnosis of psychogenic ED, while Rigiscan accuracy constitute 100\%. Among the studied 100 cases, the final and conculosive diagnoses of their complaint of erectile dysfunction using the designed sheet $\&$ series of investigation, there were 51 cases having psychological causes of ED \& 49 cases having organic causes of ED of different causes as shown in Table 7.

Table 7 Showing the final diagnosis of ED of the 100 studied patients

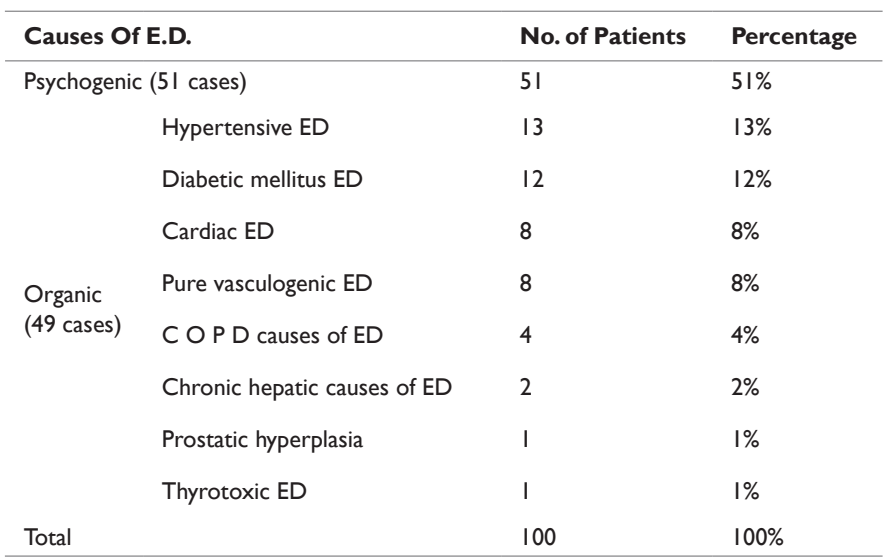


Frequencies of different organic diseases which lead to organic ED among 49 cases of the present study were shown in Table 8 \& Figure 1. There were highly significant results between type of ED and age groups as shown in Table $9 \&$ Figure 2, also highly significant results between type of ED and onset of occurrence of ED as shown in Table 10 \& Figure 3. Where the occurrence of psychogenic ED were more common since marriage and had acute onset, in contrast the organic ED that have mostly gradual onset \& highly significant results between organic ED and special habits as shown in Table 11 \& Figure 4.

Table 8 Frequency of the different organic causes related to ED among 49 cases

\begin{tabular}{llll}
\hline Item & $\begin{array}{l}\text { Criteria of } \\
\text { classification }\end{array}$ & $\begin{array}{l}\text { No. of } \\
\text { patients }\end{array}$ & Percentage \\
\hline & Hypertension & 13 & 26.5 \\
& Diabetes Mellitus & 12 & 24.5 \\
& Cardiac diseases & 8 & 16.3 \\
$\begin{array}{l}\text { Different } \\
\text { organic } \\
\text { causes }\end{array}$ & Pure vasculogenic & 8 & 16.3 \\
& COPD & 4 & 8.3 \\
& Chronic hepatic & 2 & 4.1 \\
& diseases & 1 & 2.0 \\
& Prostatic hyperplasia & 1 & 2.0 \\
& Thyrotoxicosis & 1 & 100.0 \\
\hline
\end{tabular}

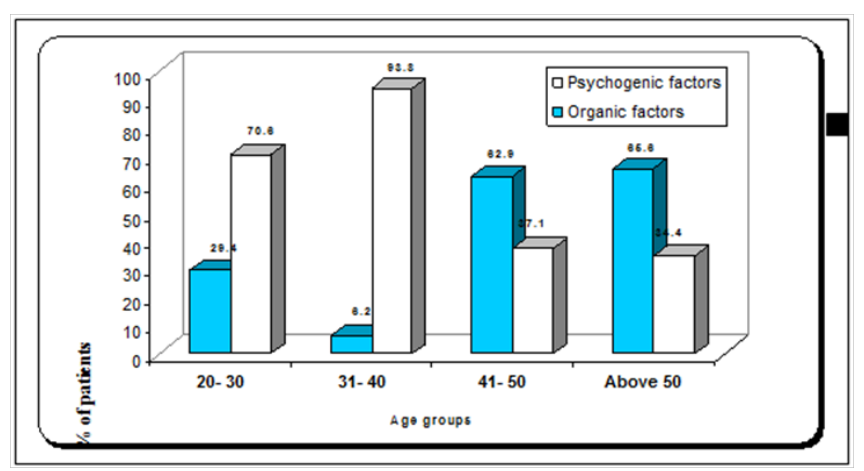

Figure I Showing the relation between the type of ED and the different age groups.

Table 9 Relation between the type of ED and age groups

\begin{tabular}{llllll}
\hline $\begin{array}{l}\text { Age groups } \\
\text { (years) }\end{array}$ & \multicolumn{2}{l}{ Psychogenic factors } & \multicolumn{2}{l}{ Organic factors } & Total \\
\hline $20-30$ & No. & $\%$ & No. & $\%$ & \\
$31-40$ & 12 & 70.6 & 5 & 29.4 & 17 \\
$41-50$ & 15 & 93.8 & 1 & 6.2 & 16 \\
Above 50 & 13 & 37.1 & 22 & 62.9 & 35 \\
Total & 11 & 34.4 & 21 & 65.6 & 32 \\
\hline
\end{tabular}

$X^{2}=20.540 ; P$-value $=0.000 * *$ Highly significance.

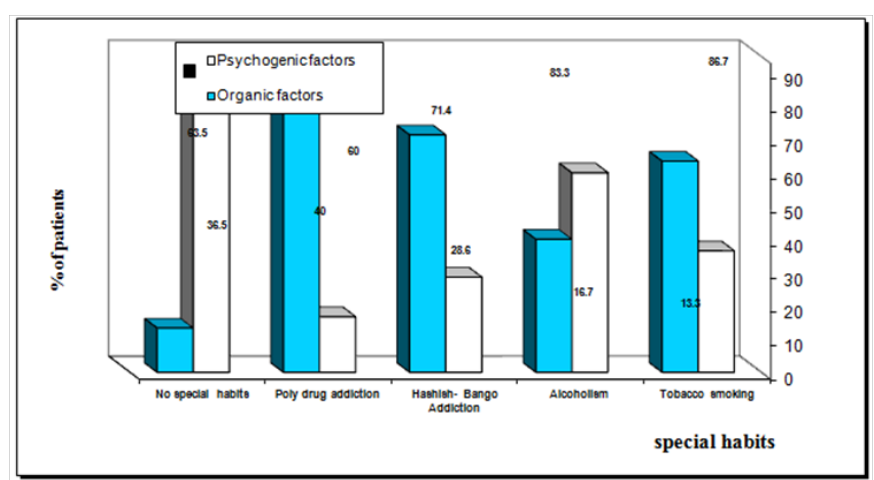

Figure 2 Showing the relation between the type of ED and special habits.

Table 10 Relation between the type of ED and special habits

\begin{tabular}{llclll}
\hline Special habits & \multicolumn{2}{l}{$\begin{array}{l}\text { Psychogenic } \\
\text { factors }\end{array}$} & $\begin{array}{l}\text { Organic } \\
\text { factors }\end{array}$ & Total \\
\hline & No. & $\%$ & No. & $\%$ & \\
Tobacco smoking & 19 & 36.5 & 33 & 63.5 & 52 \\
Alcoholism & 3 & 60 & 2 & 40 & 5 \\
$\begin{array}{l}\text { Hashish- Bango } \\
\text { Addiction }\end{array}$ & 2 & 28.6 & 5 & 71.4 & 7 \\
$\begin{array}{l}\text { Poly drug addiction } \\
\text { No special habits }\end{array}$ & 1 & 16.7 & 5 & 83.3 & 6 \\
Total & 26 & 86.7 & 4 & 13.3 & 30 \\
\hline
\end{tabular}

$X^{2}=24.025 ;$ P-value $=0.000 * ;$ *Highly significance.

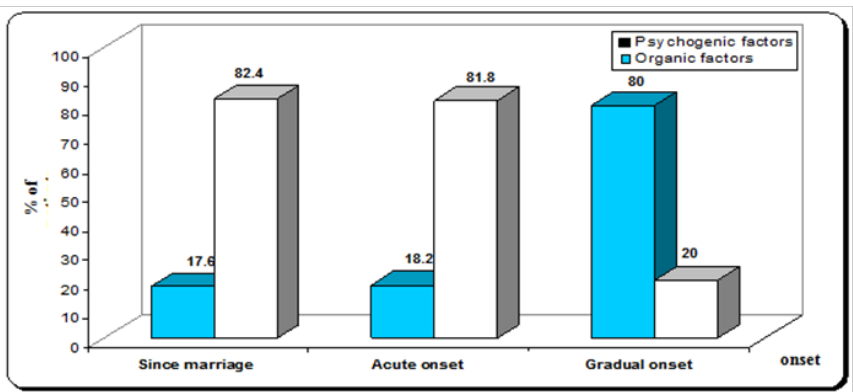

Figure 3 Showing the relation between the type of ED and onset of occurrence.

Table I I Relation between the type of ED and onset of occurrence

\begin{tabular}{llllll}
\hline Onset of ED & \multicolumn{2}{l}{$\begin{array}{l}\text { Psychogenic } \\
\text { factors }\end{array}$} & \multicolumn{2}{c}{ Organic factors } & Total \\
\hline Science marriage & 14 & $82.40 \%$ & 3 & $17.60 \%$ & 17 \\
Gradual onset & 10 & $20.00 \%$ & 40 & $80.00 \%$ & 50 \\
Total & 51 & & 49 & & 100 \\
\hline
\end{tabular}

$X^{2}=38.457 ; P$-value $=0.000 * ;$ Highly significance. 

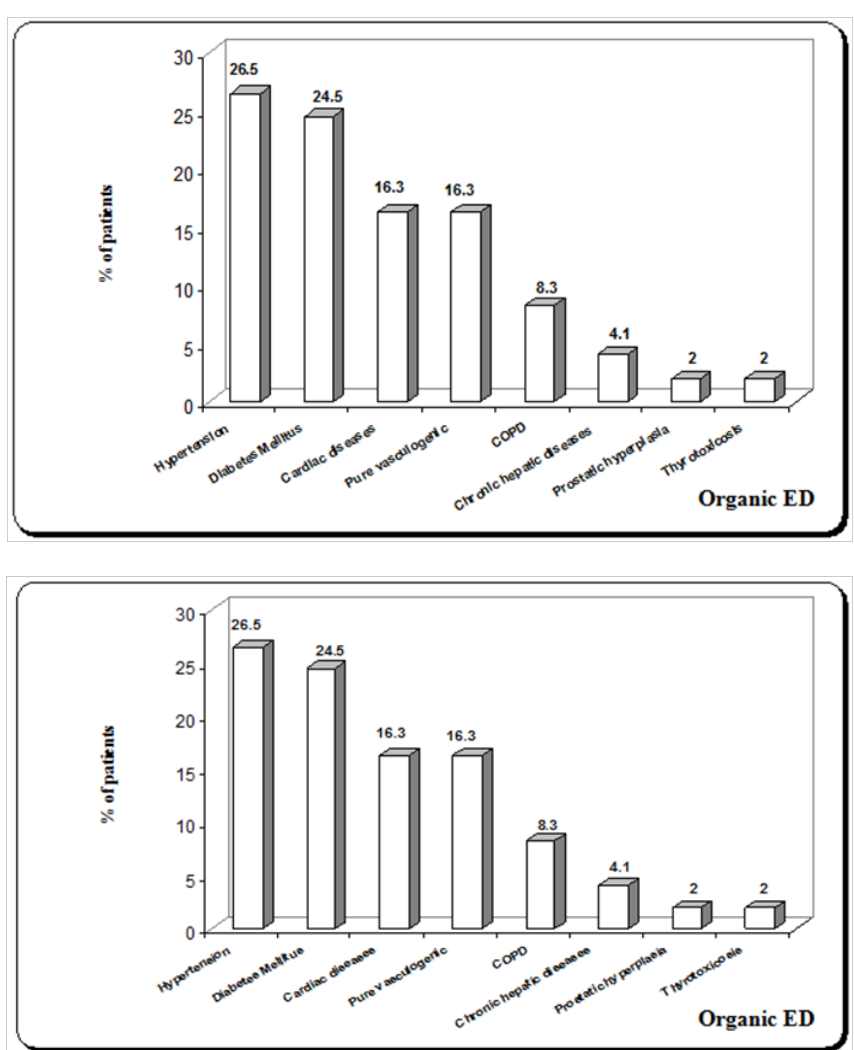

Figure 4 Frequency of the different organic causes related to ED among 49 cases.

\section{Discussion}

Erectile dysfunction threatens family life, and thus it is an important topic in male health. ${ }^{12}$ It affects man's interactions with his family and associations..$^{13}$ So the objective of this study is to design scheme for conclusive diagnosis of male sexual dysfunction, also to differentiate between the treatable and the untreatable cases by using the recent diagnostic method. The results of this study revealed that organic causes of ED were common in old ages, while psychogenic ED was common in young ages. This results agree with Mckinlay ${ }^{14}$ who reported that ED of organic etiology affecting $65 \%$ of men by the age of 45 years, while ED of psychogenic etiology affecting $70 \%$ of men under age of 40 years, and the incidence of ED may be triple form $5 \%$ to $15 \%$ between the ages of 40 and 70 years. ${ }^{14}$ In the same line, Blanker et al., ${ }^{15}$ reported that, ED is a common condition with a prevalence increases dramatically with age due to the accumulation of risk factors such as progressive decrease in free testosterone levels with age that is associated with decrease in libido. Also with aging, the prevalence of systemic diseases as cardiovascular, diabetes and prostatic tumors increase, and so the prevalence of depression and taking therapeutic drugs which affect the penile erection increase. ${ }^{15}$ The present study reveals significant results among organic ED and special habits and this result agrees with Mc Vary et al., ${ }^{16}$ who found that the endothelial vascular system all over the body affected by smoking which can lead to ED. ${ }^{16}$

Also Seftel et al., ${ }^{1}$ reported that alcoholism leads to alcoholic liver cirrhosis and ED. ${ }^{1}$ While Morales said that tobacco smoking, large acute doses of cannabis (Hashish) or chronic use of it, long term narcotic use, physical dependence of cocaine, amphetamine and alcoholism cause decreased libido and seriously interfere with normal erectile function and lead to ED. ${ }^{17}$ This study revealed a significant result among types of ED and onset of occurrence. This result agrees with Hellstrom who reported that, the incidence of psychogenic ED occurs with the onset of marriage and/or has acute onset, while the organic ED occurs with gradual onset. ${ }^{18}$ The I.C.I. testing gave $94.1 \%$ sensitivity in diagnosing the psychogenic ED. This agrees with the results of Maniam who demonstrated that, I.C.I. testing gave $95 \%$ sensitivity in diagnosing psychogenic ED in 100 patients of ED. ${ }^{19}$ Richter et al. ${ }^{20}$ said that the response to I.C.I. testing does not accurately distinguish psychogenic from organic ED, as the grades of erections obtained after I.C.I. detected roughly from E0 to E5 depending on clinical sense of physician. ${ }^{20}$ Hamed demonstrated that, there may be false results can be obtained after I.C.I. testing as it may give good response in some organic causes of ED as mild or moderate venous leakage, vasculopaths in diabetic patients, some of neurogenic and corporo-venogenic causes of ED. Also, some cases of psychogenic ED may give subnormal response due to anxiety and fear of patient. ${ }^{21}$ The final diagnosis done by using Rigiscan gives an accuracy of $100 \%$. This agrees with Lue ${ }^{5}$ who demonstrated that, NPT monitoring by Rigiscan is considered to be the most objective, non-invasive measure of erectile activity, also, it is an integral method in differentiating between psychogenic and organic ED. ${ }^{5}$ In contrast, Richter demonstrated that, there is false results may be obtained in performing Rigiscan system during the session (10 hours) due to anxiety, depression or other sleep related disorders such as sleep apnea, periodic leg movements and nocturnal myoclonus that may affect results if present in the patient during session. ${ }^{20}$

Hamed $^{21}$ demonstrated that, to avoid these false results, up to 3 sessions can be monitored by Rigiscan to the same patient then compare between the results obtained from the 3 results and comment. ${ }^{21}$ Boyle $^{6}$ demonstrated that, NPT monitoring should not be performed to men with significant organic factors related to $\mathrm{ED}^{6}$ As regard the final diagnostic results this study revealed that, $51 \%$ of cases diagnosed as psychogenic ED, while $49 \%$ as organic ED. this results agree with McKinlay ${ }^{14}$ who demonstrated, in his study on 100 cases of $\mathrm{ED}$, that $50 \%$ have organic factors related to $\mathrm{ED}$, while the other $50 \%$ of them have psychogenic causes. ${ }^{14}$ This study revealed that, 24 cases had vasculogenic causes of ED. Sullivan ${ }^{22}$ demonstrated that, arteriogenic causes of ED caused by any occlusive disease that affects the penile arteries in the presence of normal corporo-venogenic mechanism leading to failure of penile filling with blood and decrease in the rigidity of erection. ${ }^{22}$ This study revealed 13 cases $(26.5 \%$ of organic cases of ED) suffered from hypertension and ED. Seftel ${ }^{1}$ reported that $68.3 \%$ of men with hypertension exhibited some degree of ED, and ED was more severe in patients with hypertension than in the general population. The cause of ED of $89 \%$ of patients with hypertension is penile arterial dysfunction. ${ }^{1}$ This study revealed 12 cases $(24.5 \%$ of organic cases of ED) had diabetes mellitus and ED.

Heaton ${ }^{23}$ demonstrated that, diabetes mellitus is the most frequent hormonal cause of ED, and the poorly controlled D.M. can produce sexual dysfunction in men of all ages through its affection on both neurogenic and vascular factors, in addition to the psychological factors that may develop from anxiety in response to fear of failure..$^{23}$ This study revealed 8 cases (16.3\% of organic cases of ED) had cardiac disease and ED. Feldman ${ }^{24}$ reported that the cardiovascular diseases are risk factors of ED. ${ }^{24}$ The present study revealed 4 cases (8.2\% of organic cases of ED) had COPD and ED. McVary et al., ${ }^{16}$ demonstrated that, the respiratory diseases as sleep apnea and COPD are characterized by arterial hypoxia, hypercapnia and systemic hypertension so, there is obvious association between them and 
development of ED despite of their normal penile vasculature. ${ }^{16}$ The results of this study revealed 2 cases $(4.1 \%$ of organic cases of ED) had chronic hepatic diseases (alcoholic liver cirrhosis) and ED. Freeman ${ }^{25}$ reported that, chronic hepatic diseases as alcoholic liver cirrhosis cause hepatic aromatization of testosterone to estrogen leading to estrogen excess in blood that cause lutenizing hormone (L.H.) suppression, lowering of serum testosterone levels and cause ED. ${ }^{25}$ This study revealed 1 case ( $2 \%$ of organic cases of ED) had hyperthyroidism (thyrotoxicosis) and ED. Hedon reported that hyperthyroidism can impair potency of erection and the mechanism of that is thought to be an increase in the binding protein for testosterone which leads to decrease in serum testosterone level. ${ }^{26}$

This study revealed 1 case ( $2 \%$ of organic cases of ED) had prostatic hyperplasia and ED. Seftel et al., reported that, the prevalence rate of ED was $18 \%$ for men aged $50-59$ years in the general population according to the National Health and Social Life Surgery due to prostatic hyperplasia and cancer prostate, in addition to the prevalence of benign prostatic hyperplasia (BPH) increases with age and so the risk for ED. ${ }^{1}$ As regard medications related to development of ED, it was found that 13 cases were on antihypertensive drug therapy. Goldstein $^{27}$ demonstrated that, antihypertensive drug have been accused of interfering penile erection and impairs libido through reduction of perfusion pressure. ${ }^{27}$ In contrast, Morales ${ }^{28}$ reported that angiotensin converting enzyme inhibitors (ACE) are not known to cause sexual dysfunction and they are save drugs. ${ }^{28}$ For psychogenic ED, Seidman et al. ${ }^{29}$ demonstrated that, the treatment of psychogenic ED is possible and includes; behavioral, cognitive, physical and interpersonal communications. ${ }^{29}$ So, psychogenic ED needs psychotherapy in addition to physical lines of therapy. They also demonstrated that, psychotherapy should be done through couple therapy to improve all aspects of the relationship between the partners and detecting the sexual problems between them during sessions to help the partners to concentrate on sexual sensations and satisfaction leading to reduction in the performance anxiety and pressures.

In the same line $\operatorname{Eid}^{30}$ reported that, physical lines of therapy are very successful to psychogenic ED, and it include; oral erectogenic drugs either centrally acting or peripherally acting. Also, the intracavernusal injection (I.C.I) therapy by vasoactive drugs and the vacuum constriction device (VCD) may be indicated. Penile prosthesis implantation may be indicated in some cases in psychogenic ED especially after failure of prolonged sex therapy and in sever psychiatric disturbances. ${ }^{30}$ For organic ED, Seftel et al., ${ }^{1}$ demonstrated that, it is essential to correct and control systemic causes related to ED. The physical lines of therapy to correct ED such as oral erectogenic drugs, vacum constrecting device (VCD), I.C.I. therapy and finally penile prosthesis implantation can be used. The choice among these therapeutic trials depends on the severity and degree of ED. ${ }^{1}$ Hartman $^{31}$ said that, there is a psychogenic type of ED on top of organic type; for example, a diabetic male who has an episodic problem of erectile failure, over time, develop erectile problem associated with his fear of failure. This performance anxiety in response to the fear of failure may result in a psychogenic erectile disorder, but the organic impairment during the evaluation as it gives weak response to (I.C.I.) testing and abnormal results to (NPT) monitoring by Rigiscan. ${ }^{31}$

\section{Recommendations}

I. For the conclusive diagnosis and differentiation between psychogenic and organic ED, the present clinical diagnostic sheet of male sexual dysfunction should be applied (see Arabic summary).
II. Using Rigiscan is the best available and objective test to differentiate between ED of organic and psychogenic etiologies.

III. The use of Rigiscan system should be under direct observation of the medico-legal department of ministry of Justice and its experts, to be sure that there is justice in performing this system in the cases of ED.

IV. The cases of ED must be reassessed after 1 year.

V. This study considered the following cases are hopeless cases:

i. The organic hopeless cases as absent penis, micropenis, severely damaged or amputated testes, failed all therapeutic trials, or the only therapeutic trial is penile prosthesis implantation and the wife refuses the sexual life with this mechanical erection,

ii. The psychogenic hopeless cases need psychiatric treatment for a long time (years) or need psychological drug therapy that affects erectile function.

\section{Acknowledgments}

None.

\section{Conflicts of interest}

The author declares that there are no conflicts of interest.

\section{References}

1. Seftel AD, Harmin PN, Weisberg R, et al. "Male and female sexual dysfunction", Textbook of sexual dysfunction. 2005.

2. Johnson RD. Brainstem micro stimulation differentially inhibits pudendal motoneuron reflex inputs. Neuroreport. 1998;9(2):341-349.

3. Saenz de Tejada I, Gonzalez Cadavid N, Heaton J, et al. Anatomy, physiology and path physiology of erectile dysfunction. In: Jardin A et al, editors. Erectile dysfunction. Plymouth, UK: Health Publication. 1999;67-102.

4. Rosen R, Seidman M. Medical and psychological interventions for erectile dysfunction: towards a combined treatment approach. In: Lieblum S, Rosen R, editors. Principles and practice of sex therapy: update for 2000. New York: Guilford Press. 2001;276-295.

5. Lue TF, Tanagho EA, Schmidt R. Erectile dysfunction. $N$ Engl J Med. 2000;342(24):1802-1813.

6. Boyle P. Some observations on the epidemiology of male erectile dysfunction. Textbook of erectile dysfunction. 2000.

7. Braun M, Wassmer G, Klotz T, et al. Epidemiology of erectile dysfunction: results of the Cologne Male Survey. Int J Impit Res. 2000;12(6):305-371.

8. Virag R. Arterial and venous hem dynamics in male impotence. Williams \& Wilkins, Baltimore. 1982;108-119.

9. Sandhu D, Curless E, Dean J, et al. A double blind, placebo controlled study of intra cavernously vasoactive intestinal polypeptide and phentolamine mesylate in a novel anto-injector for the treatment of non- psychogenic erectile dysfunction. Int J Impot Res. 1999;11(2):91-99.

10. Lue TF, Hricak H, Marich K. Physiology of erection and pharmacology management of impotence. J Urol. 1998;137(5):829-836.

11. Bradly WE, Timm GW. New method for continuous measurement of NPT and rigidity. Urology. 1995;26(1):40.

12. Pommerville P. Erectile dysfunction, an over view. Can J Urol. 2003;1:2-6.

13. Miller TA. Diagnostic evaluation of erectile dysfunction. American Family Physician. 2000;61(1):95-104. 
14. McKinlay JB. The worldwide prevalence and epidemiology of erectile dysfunction. Int J Import Res. 2000;12(4):S6-S11.

15. Blanker MH, Runda Bosch JLH, Groeneveld FPMJ, et al. Erectile and ejaculatory dysfunction in a community-based sample of men 50 to 78 years old: prevalence, concern and relation to sexual activity. $J$ Urology. 2001;57(4):763-768.

16. McVary KT, Carrier S, Wessells H. Smoking and erectile dysfunction: evidence based analysis. J Urol. 2001;166(5):1624-1632.

17. Morales A, Condra M, Reid K. The role of nocturnal penile tumescence monitoring in the diagnosis of impotence. A review $J$ Urol. 2002;143(3):441-446.

18. Hellstrom WJG, Bivalacqua TJ, Honlmes SA, et al. Peyronie's disease: etiology, medical and surgical therapy. J Androl. 2004;21(3):347-354.

19. Maniam P, Seftel AD, Corty EW, et al. Nocturnal penile tumescence activity unchanged after long-term intra-cavernous injection therapy. $J$ Urol. 2001;165(3):830-838.

20. Richter S, Vardi Y, Ringel A, et al. Intracavernous injections: still the gold standard for treatment of erectile dysfunction in elderly men. Int J Impot Res. 2001;13(3):172-179.

21. Hamed Abdalla Hamed. Simplified textbook for the male erectile dysfunction. 2006.

22. Sullivan ME, Keoghan SR, Miller MAW. Vascular risk factors and erectile dysfunction. Br J Urol Int. 2001;87(9):838-845.
23. Heaton JP, Lording D, Liu SN, et al. Intracavernosal alprostadil is effective for the treatment of erectile dysfunction in diabetic men. Int J Impot Res. 2001;13(6):317-341.

24. Feldman HA, Johannes CB, Berby CA, et al. Erectile dysfunction and coronary risk factors: prospective results from the Massachusetts Male Aging Study. Prev Med. 2000;30(4):328-338.

25. Freeman ER, Bloom DA, McGuire EJ. A brief history of testosterone. $J$ Urol. 2001;165(2):371-373.

26. Hedon F. Anxiety and erectile dysfunction: a global approach to ED enhances results and quality of life. International Journal of impotence research. 2003;15(2):516-519.

27. Goldstein I. The mutually reinforcing triad of depressive symptoms, cardiovascular disease and erectile dysfunction. Am $J$ Cardial. 2000;86(2A):41F-45F.

28. Morales A. Yohimbine in erectile dysfunction. The facts Int J Impot Res. 2000;12(1):S70-S74.

29. Seidman SN, Roose SP, Menza MA, et al. Treatment of erectile dysfunction in men with depressive symptoms: results of a placebo controlled trial with sildenafil citrate. Am J Psychiatry. 2001;158(10):1623-1632.

30. Eid JF. Present and future management of erectile dysfunction: treatment options. UAU Annual convention. 2005;12(4):62-69.

31. Hartmann U. Psychological subtypes of erectile dysfunction results of statistical analyses and clinical practice. World J Urol. 1997;15(1):56-70. 